\title{
EDUCAÇÃO BÁSICA COM INTERMEDIAÇÃO TECNOLÓGICA: UM MECANISMO DE AÇÃO SOCIAL, DEMOCRATIZAÇÃO E INCLUSÃO SOCIODIGITAL NA ZONA RURAL DO ESTADO DA BAHIA
}

\author{
SALVADOR/BA JUNHO/2018
}

\author{
Letícia Machado dos Santos - SEC/BA - Imachado.ead@gmail.com \\ Helisangela Acris Borges de Araújo - SEC/BA - helisangela.araujo@educacao.ba.gov.br \\ Silvana de Oliveira Guimarães - SEC/BA - silvana.guimaraes@educacao.ba.gov.br \\ Marcus Túlio de Freitas Pinheiro - UNEB/BA - mtpinheiro@uneb.br
}

Tipo: Investigação Científica (IC)

Natureza: Descrição de Projeto em Andamento

Categoria: Métodos e Tecnologias

Setor Educacional: EDUCAÇÃO MÉDIA E TECNOLÓGICA

\begin{abstract}
RESUMO
A educação é o cerne para o desenvolvimento de uma sociedade, e a modalidade de Educação a Distância (EaD), com currículo e práticas educativas bem planejadas, com uso dos processos tecnológicos, poderá resultar em uma boa atuação pessoal e profissional desses estudantes, além de desenvolver sua autonomia. Além disto, a presente pesquisa, que já se encontra em desenvolvimento, pode colaborar com a educação brasileira a distância, abrangendo sua utilização como modalidade de educação formal na educação básica, disseminando sua utilização como fator de desenvolvimento humano de ação social, democratização e inclusão sociodigital na zona rural. Constatou-se, ainda, no levantamento bibliográfico e em congressos sobre a temática, uma escassez em materiais que versem sobre $o$ assunto, especialmente no que tange a educação básica, sendo outro ponto que justifica a relevância da pesquisa aqui apresentada. O principal objetivo é Apresentar as contribuições do Ensino Médio com Intermediação Tecnológica (EMITec) como ação social no processo de formação de alunos residentes em localidades de difícil acesso do Educação Básica no estado da Bahia, entre os anos de 2011 e 2018. Metodologicamente optou-se por uma pesquisa bibliográfica e de campo, com um estudo de caso, fazendo uso de levantamento de dados e da metodologia de emergência de conceitos. $O$ aporte teórico contou com Delors (1996), Santos (2008), Santos; Oliveira (2011), Pinheiro (2012) e Libâneo (2013).
\end{abstract}

Palavras-chave: Ação social. Aprendizagem interativa e colaborativa. Desenvolvimento humano. Educação a Distância (EaD). Inclusão sociodigital. Intermediação tecnológica. 


\section{INTRODUÇÃO}

A temática "intermediação tecnológica na educação básica" é de relevância acadêmica e de impacto para o contexto social/científico, uma vez que a educação exerce um papel fundamental nas relações humanas, e é dentro deste contexto social que o indivíduo se desenvolve pessoal e profissionalmente. A Educação por intermediação tecnológica é uma das formas de contribuição para esta formação. Para Santos (2008, p. 69-70), a expansão desta modalidade educativa deve-se ao desenvolvimento de um currículo flexível, com práticas interdisciplinares e dinâmico, além do uso adequado dos recursos tecnológicos, fazendo com que "[...] o aluno deixe de ser o receptor de informações para tornar-se o responsável pela construção de seu conhecimento, usando o computador.". O Programa em questão, atualmente, atende a um público de 21.000 (vinte e um) mil estudantes residentes em localidades de difícil acesso da zona rural, comunidades quilombolas e indígenas, fazendo uso de uma solução tecnológica viabilizada por uso de uma plataforma de telecomunicações via satélite com o software IP.TV (Internet Protocol Television), que inclui recursos como videoconferência (Figura 1), permitindo a articulação entre processos pedagógicos, metodologia inovadora e tecnologia atual, que faculta a inserção dos assistidos por essa estratégia na dinâmica mundial (BAHIA, 2018).

Figura 1. Infraestrutura tecnológica do Ensino Médio com Intermediação Tecnológica -EMITec/SEC/BA

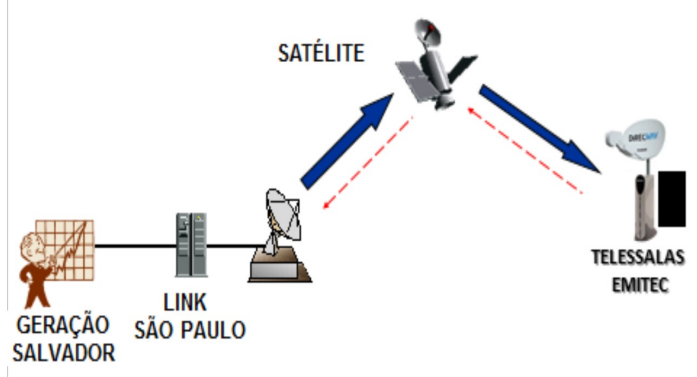

Fonte: EMITEC/SEC/BA, 2018.

Tal metodologia estimula a construção do conhecimento, mediante o trabalho investigativo, cooperativo e de integração de grupos, criando um ambiente propício e incentivador da criatividade e aprendizagem. Nesse processo, a (re)significação de conceitos e a consequente construção do conhecimento poderá ocorrer de forma interativa e colaborativa (VYGOTSKY, 2008).

\section{OBJETIVO GERAL:}


Apresentar as contribuições do Ensino Médio com Intermediação Tecnológica (EMITec) como ação social no processo de formação de alunos residentes em localidades de difícil acesso do Educação Básica no estado da Bahia, entre os anos de 2011 e 2018.

\section{OBJETIVOS ESPECÍFICOS:}

Identificar e analisar os pressupostos teóricos e metodológicos da proposta pedagógica do EMITec, buscando conhecer suas contribuições para o desenvolvimento humano dos estudantes; Avaliar o processo de expansão do EMITec para diferentes municípios e localidades do Estado da Bahia, no período de 2011 a 2018; Analisar as taxas de matrícula, aprovação, reprovação, abandono e conclusão do Ensino Médio, através do EMITec, no período de 2011 a 2018.

\section{REFERENCIAL TEÓRICO}

Uma das definições mais abrangente de ação social é aquela que a conceitua como uma ação orientada pelas ações dos outros. Para Gonzalez (2002), entretanto, nem toda ação é uma ação social, uma vez que uma ação é um comportamento humano em que os indivíduos se relacionam com um sentido subjetivo. Já a ação social é a orientação do comportamento do indivíduo levando em conta o comportamento dos outros indivíduos, que podem ser conhecidos ou desconhecidos do indivíduo em questão. Assim, Gonzalez (2002) conclui que uma relação social é todo comportamento cuja origem depende da reação ou da expectativa de reação de outras partes envolvidas. Essas "outras partes" podem ser indivíduos ou grupos, próximos ou distantes, conhecidos ou desconhecidos de quem realiza a ação.

Nesta perspectiva, a ideia central da ação social é a existência de um sentido na ação: ela se realiza de uma parte (agente) para outra. É uma atitude sobre a qual recai ao menos um desejo de intercâmbio, de relacionamento, como acontece na EaD. Assim, toda relação social é determinada não só pelos resultados para o agente, mas também pelos efeitos (reais ou esperados) que pode causar ao outro (GONZALEZ, 2002).

Uma divisão clara entre ações que podem e não podem ser consideradas sociais é impossível de ser estabelecida. Para entendermos se uma ação é social, devemos prestar atenção no contexto em que ela ocorre. Assim, a EaD pode ou não ser considerada uma ação social e inclusiva. Devemos, entretanto, ter cuidado para não torná-la exclusiva, no âmbito de sua atuação. Daí a necessidade de políticas públicas voltadas para o ensino a distância em suas diversas vertentes como educação continuada, educação básica e educação superior, como uma ação social tradicional e 
ao mesmo tempo racional com relação a valores e fins.

No tocante à $\mathrm{EaD}$, podemos considerá-la como uma ação social de elevado custo tecnológico e importância, tendo como finalidade erradicar a falta de oportunidade de acesso à educação básica e superior, uma vez que $84 \%$ dos brasileiros não possuem curso superior (ENAP, 2006). Educar a distância é democratizar o ensino no país e facilitar o acesso à formação profissional, além da inclusão digital. Com isto, a EaD tornou-se altamente sintonizada com um mundo globalizado que rompeu com as dimensões de tempo e espaço, permitindo que as pessoas entrem no mercado de trabalho e se sintam incluídas socialmente.

Desta forma, em uma ação social, cujo cerne é a educação e o agente a ser transformado é o estudante, a atuação docente deve ser transformadora. Sobre esta questão Santos e Radike, (2005, p. 328) argumentam:

Na perspectiva transformadora de uso do computador na educação, a atuação do docente não se limita a fornecer informações aos alunos. Cabe a ele assumir a mediação das interações docentes-alunos-computador, de modo que o aluno possa construir o seu conhecimento em um ambiente desafiador, em que o computador auxilie, promovendo o desenvolvimento da autonomia, da criatividade e da autoestima do aluno.

O aluno deixa de ser o receptor de informações para tornar-se o responsável pela construção de seu conhecimento, usando o computador para buscar, selecionar, interrelacionar informações significativas, de forma colaborativa, na exploração, reflexão, representação e depuração de suas próprias ideias, segundo seu estilo de pensamento. Professores(as) e alunos(as) desenvolvem ações em parceria, por meio da cooperação e interação com o contexto, com o meio ambiente e com a cultura circundante.

Com o avanço tecnológico, no século XXI, a EaD ganhou maior condição de qualidade graças às inúmeras possibilidades de instrumentos, estratégias de aprendizagem e facilidade de acesso aos mecanismos que fazem com que o ensino e aprendizagem seja levado aos locais mais distantes. O avanço tecnológico coloca a educação diante de novos desafios:

[...] trata-se de um novo fazer pedagógico, fundamentado em um paradigma educacional emergente, o qual coloca uma nova maneira de pensar a educação. Esses novos caminhos revelam uma ruptura com as práticas tradicionais e avançam em direção a uma ação pedagógica interdisciplinar voltada para a aprendizagem do(a) aluno(a) - sujeito envolvido no processo não somente com o seu potencial cognitivo, mas com todos os fatores que fazem parte do ser unitário, ou seja, também os fatores afetivos e sociais (SANTOS; RADIKE, 2005, p. 328).

Neste cenário, a intermediação tecnológica se configura como uma modalidade de educação relativamente nova no Brasil e em franca expansão, principalmente na 
educação básica. É uma prática que permite, de forma presencial e virtual, o equilíbrio entre as necessidades e habilidades individuais e grupais. Nessa perspectiva, é possível avançar rapidamente, trocar experiências, esclarecer dúvidas e inferir resultados. É nesta modalidade educacional que o Ensino Médio com Intermediação Tecnológica (EMITec) encontra-se inserido. Pioneiro na região nordeste do país, a qual amarga os piores índices do Índice de Desenvolvimento da Educação Básica (IDEB), principalmente na zona rural.

Assim, o EMITec propõe a criação de uma proposta didático-pedagógica inovadora para solucionar problemas educacionais para um Estado de grande territorialidade e desigualdades socioculturais, tendo ainda como base no TíTULO VI - Organização da Educação Básica; CAPÍTULO I - Etapas da Educação Básica; Seção III - Ensino Médio Art. 26. § $3^{\circ}$ :

Os sistemas educativos devem prever currículos flexíveis, com diferentes alternativas, para que os jovens tenham a oportunidade de escolher o percurso formativo que atenda seus interesses, necessidades e aspirações, para que se assegure a permanência dos jovens na escola, com proveito, até a conclusão da Educação Básica (BRASIL, 1994, p. 45).

Para que essa prática educativa possa ser vivenciada tanto pelo educador quanto pelo educando, torna-se necessário um conhecimento maior do uso da intermediação tecnológica no processo educacional e do currículo do ensino médio e, portanto, o desenvolvimento de habilidades para o uso competente dos recursos tecnológicos. Ao professor cabe o papel de ser mediador das interações docente-aluno-computador, de modo que o aluno possa tornar-se responsável pela construção de seu conhecimento, usando os processos tecnológicos, promovendo sua autonomia, criatividade e autoestima (SANTOS; OLIVEIRA, 2011).

Nesse ponto de vista, o EMITec vem realizando o que já é defendido por diversos autores, a exemplo de Santos (2008), que, em sua Dissertação de Mestrado, manifestase em favor das inúmeras possibilidades de uso positivo destes recursos na educação, não apenas como oportunidade de acesso ao Ensino Superior. Também Rabelo (2006, p. 75), coloca-se nessa defesa ao argumentar que a utilização das Tecnologias de Informação e Comunicação (TIC) possibilitará: "[...] não só o atendimento a grandes contingentes de alunos, dispersos geograficamente, mas também a igualdade de oportunidades educativas e, consequentemente, a inclusão social.”.

De acordo com Delors (1996, p. 147), esses sistemas educativos devem "[...] recorrer a meios suplementares e a métodos pedagógicos especiais a favor de públicos alvo e de estabelecimentos situados em zonas urbanas ou suburbanas desfavorecidas, como já 
se faz em numerosos países [...].". Santos (2008, p. 32) complementa, afirmando que os sistemas educativos, ao aliar a aplicação tecnológica à área educacional, serão capazes de "[...] proporcionar um crescimento real nos indicadores de desenvolvimento humano, uma vez que possibilitarão gerar um aumento significativo da igualdade de oportunidades, pois diminuirão as diferenças.". Nesse sentido, pode-se esperar que a utilização de recursos tecnológicos na educação possa gerar informação e conhecimento de alta qualidade para os estudantes e professores, facilitar o desenvolvimento de sistemas de gestão do conhecimento que aperfeiçoem a administração das escolas e universidades, reflexão e flexibilidade no currículo do ensino médio, além de difundir melhores práticas educativas de forma rápida.

\section{PROCEDIMENTOS METODOLÓGICOS}

O trabalho aqui desenvolvido, do ponto de vista da abordagem do problema caracterizase como qualitativa. Para Flick (2009, p. 21) "[...] a pesquisa qualitativa é de particular relevância ao estudo das relações sociais devido à pluralização das esferas de vida. Essa pluralização requer uma nova sensibilidade para o estudo empírico das questões.".

Metodologicamente, para complementar a pesquisa de campo, a mesma foi associada a metodologia de emergência de conceitos, fazendo uso da Teoria de Vygotsky (2008). A metodologia de emergência de conceitos, de acordo com Pinheiro (2012, p. 13) "[...] é tratada a partir de conceitos geradores pré-existentes que são significados pelos atores da pesquisa gerando universos de referências para esses conceitos [...].". Nesse sentido, a presente pesquisa tem como atores principais os estudantes do EMITec em que são utilizados seus conhecimentos prévios para a construção de novos conhecimentos. Como universo da pesquisa os estudantes do EMITec no período de 2011 a 2018. Desta forma, metodologicamente, a pesquisa consta de: pesquisa bibliográfica, a metodologia de emergência de conceitos, trabalho de campo concretizado com o levantamento de dados.

\section{APRESENTAÇÃO E DISCUSSÃO DOS RESULTADOS PARCIAIS}

Entre os anos de 2011 e 2018 o EMITec evidenciou relativa linearidade no processo de implantação nos municípios, de forma que o número de municípios atendidos pelo programa variou entre 135 e 155, respectivamente, nos anos de 2018 e 2011 (Figura 2). A pouca oscilação entre o número de municípios, associada à significativa manutenção do Programa nas mesmas unidades municipais pode ser justificada pela aceitação do EMITec como modalidade aceita de oferta do Ensino Médio, de forma que os municípios 
assistidos mantêm a adesão. O fato da maioria dos municípios optar pela manutenção do programa minimiza a possibilidade de implantação em outras unidades municipais, uma vez que existem limitações orçamentárias que balizam a expansão do EMITec. Desta forma, o projeto de ampliação assegurou, basicamente, o aumento no número de localidades assistidas pelo programa, de forma que, entre os anos de 2011 e 2016 ocorreu ampliação no número de localidades assistidas pelo EMITec, passando de 292 para 431, respectivamente (Figura 2). Entretanto, nos anos de 2017 e 2018 ocorreu redução no número de localidades, possivelmente determinada pela definição de novos critérios de abertura de salas, com ampliação no número mínimo de alunos matrículados.

Figura 2. Número de municípios e localidades com turmas do EMITec no período de 2011 a 2018

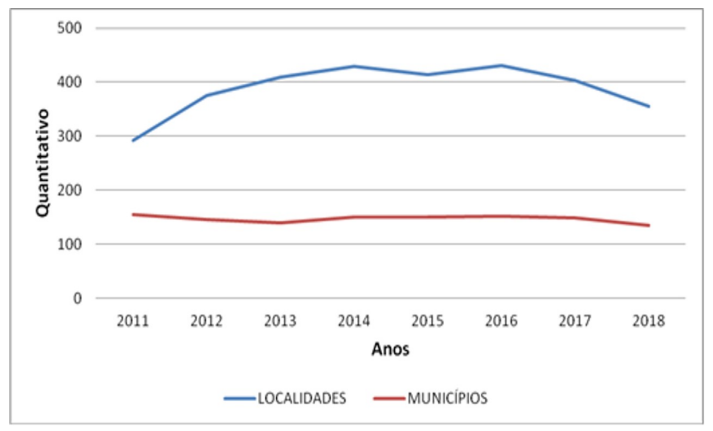

Fonte: EMITEC/SEC/BA, 2018.

Com relação ao número de matrículas, verifica-se aumento significativo no número de alunos que ingressaram no EMITec entre os anos de 2011 e 2017. A redução pouco expressiva no número de matrículas no ano de 2018 pode não retratar a realidade, uma vez que as matrículas na Rede Estadual de Educação ainda estão sendo concluidas em algumas localidades (Figura 3).

Figura 3. Número de matrículas no EMITec, no período de 2011 a 2018

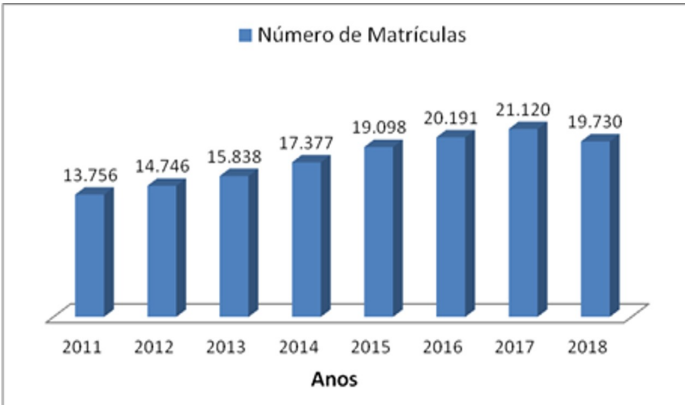


Fonte: EMITEC/SEC/BA, 2018.

No EMITec destaca-se o reduzido número de abandono, que passou de 7,38\% para 3,25\%, entre os anos de 2011 e 2017 (Figura 4). A baixa taxa de abandono ratifica a importância do programa para os alunos que, residindo em localidades distantes dos centros urbanos, vêm no Ensino Médio com Intermediação Tecnológica a possibilidade de concluírem a formação básica., Outros dados que merecem destaque são o baixo índice de reprovação e a elevada taxa de aprovação. A reprovação, ao longo dos anos de 2011 e 2017, foi sempre inferior a 7\% do número de alunos matriculados, chegando a tingir seu menor patamar no ano de 2014, com percentual de 3,28\%. Em geral, a taxa de aprovação tem sido superior a 85\%, com maior percentual no ano de 2017 (95,09\%).

O alto índice de aprovação pode ser explicado pelo fato do programa apresentar diferentes ferramentas de aprendizagem, de forma que os alunos, além das aulas ao vivo, podem contar com o acesso as aulas editadas, que ficam disponíveis no Ambiente Educacional Web (AEW). Além das referidas ferramentas de ensino e aprendizagem, o sistema de avaliação do programa caracteriza-se por apresentar caráter processual e inovador, que motiva o estudo, através da realização de atividades contextualizadas, de natureza teórico-prática.

Figura 4. Número de aprovados, reprovados e abandono no EMITec no período de 2011 a 2017

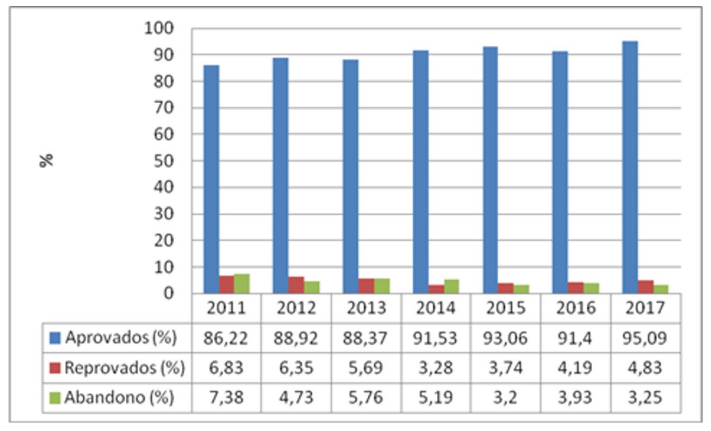

Fonte: EMITEC/SEC/BA, 2018.

O mesmo crescimento observado no número de matrículas, no período de 2011 a 2016, foi verificado no número de alunos concluintes do Ensino Médio, com pequeno decréscimo no ano de 2017 (Figura 5). No decorrer de 2011 a 2017, o EMITec promoveu a conclusão do Ensino Médio para 32.961 alunos, com destque para o ano 2016, quando 6.265 alunos concluíram a formação do ensino básico através desta modalidade de ensino. 
Figura 5. Número de concluintes do Ensino Médio através do EMITec

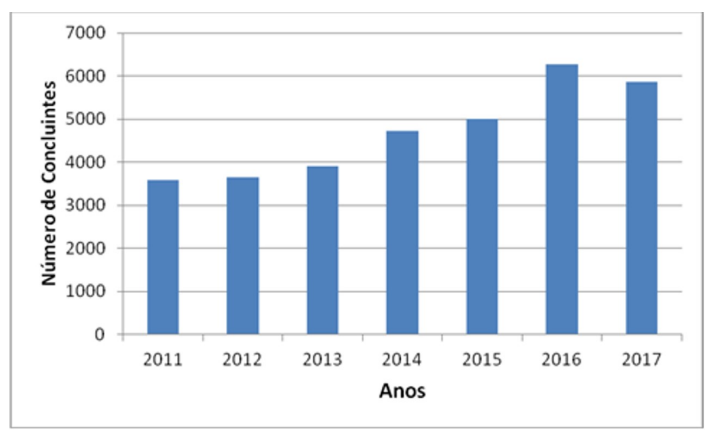

Fonte: EMITEC/SEC/BA, 2018.

\section{CONSIDERAÇÕES FINAIS}

Diante dos dados apresentados neste trabalho fica evidente que o Ensino Médio com Intermediação Tecnológica (EMITec) vem trazendo resultados positivos no cenário educacional e com evidentes impactos no contexto social das localidades atendidas no estado da Bahia, uma vez que sua proposta pedagógica e inovadora vem articulando saberes teóricos e práticos a partir do uso efetivo das tecnologias aliadas a comunicação e educação. O EMITec apresentou um crescimento expressivo de alunos matriculados na rede regular de ensino nos anos de 2011 a 2017 conforme resultados aqui apresentados, com metodologias ativas baseada em competências e no respeito a diversidade cultural e identitária dos sujeitos vinculados a esta modalidade de ensino.

Ao longo destes anos de trabalho verificou-se também um alto índice de aprovação e, concomitantemente, baixos índices de reprovação e abandono, estas taxas se devem a estratégias pedagógicas diversificadas permanentemente, o uso de temas transversais associados aos conteúdos dos diferentes componentes curriculares, dentre outras ações que reforçam a aprendizagem significativa e colaborativa dos sujeitos envolvidos, viabilizando a conclusão da educação básica, continuidade do estudo e inclusão social dos alunos vinculados ao EMITec.

\section{REFERÊNCIAS}

ALVES, Lynn. NOVA, Cristiane.(orgs). Educação a Distância: uma nova concepção de aprendizado e interatividade. São Paulo: Futura, 2003.

BAHIA. Secretaria de Educação do Estado da Bahia. IP.TV - Estúdio 1 ,2 e 3, Salvador, 2011. 
BRASIL. Presidência da República. Casa Civil. Lei n 9.394/96, de 20 de dezembro de 1996. Estabelece as diretrizes e bases da educação nacional. Brasília, 1996. Disponível em: . Acesso em: 18 maio 2017.

DELORS, Jacques (Org.). Educação: um tesouro a descobrir - Relatório para a UNESCO da Comissão Internacional sobre Educação para o Século XXI. São Paulo: Cortez, 1996.

FLICK, Uwe. Desenho da pesquisa qualitativa. Tradução Catalgo Costa. Porto Alegre: Artemed, 2009.

NEWMAN, Fred; HOLZMAN, Lois. Lev Vygotsky cientista revolucionário. São Paulo: Loyola, 2002.

ORNELLAS, Maria de Lourdes; OLIVEIRA, Maria Olívia de Matos (Orgs.). Educação, tecnologia e representações sociais. Salvador: Quarteto, 2007.

PINHEIRO Marcus Túlio de Freitas. O conhecimento enquanto campo: o Ente Cognitivo e a emergência de conceitos. Tese de doutorado do Programa de Pós-Graduação em Educação, da Universidade Federal da Bahia. 2012, 220 p.

SANTOS, Letícia Machado dos. Licenciatura em Biologia: impactos de um curso a distância para os estudantes nos planos pessoal e profissional. 2008. 160 f. Dissertação (Mestrado Profissional Multidisciplinar em Desenvolvimento Humano e Responsabilidade Social) - Centro de Pós-Graduação e Pesquisa Visconde de Cairu, Fundação Visconde de Cairu, 2008.

SANTOS, Letícia Machado. OLIVEIRA, leda Pinheiro da Silva. Ensino Médio com Intermediação Tecnológica: uma proposta didático-pedagógica para as séries finais da educação básica - Ensino Médio no Estado da Bahia. In: ROCHA, Nívea Maria Fraga. RABELO, Patrícia Fraga Rocha (Org.). Educação, desenvolvimento humano e responsabilidade social: fazendo recortes na multidisciplinaridade. Salvador: Fast Design, 2011. p. 37-53. 